\title{
Democratic Accountability and Retrospective Voting: A Laboratory Experiment*
}

\author{
Jonathan Woon ${ }^{\dagger}$ \\ University of Pittsburgh \\ February 15, 2012 \\ Forthcoming, American Journal of Political Science
}

\begin{abstract}
Understanding the incentives of politicians requires understanding the nature of voting behavior. I conduct a laboratory experiment to investigate whether voters focus on the problem of electoral selection or if they instead focus on electoral sanctioning. If voters are forward-looking but uncertain about politicians' unobservable characteristics, then it is rational to focus on selection. But doing so undermines democratic accountability because selection renders sanctioning an empty threat. In contrast to rational choice predictions, the experimental results indicate a strong behavioral tendency to use a retrospective voting rule. Additional experiments support the interpretation that retrospective voting is a simple heuristic that voters use to cope with a cognitively difficult inference and decision problem and, in addition, suggest that voters have a preference for accountability. The results pose a challenge for theories of electoral selection and voter learning and suggest new interpretations of empirical studies of economic and retrospective voting.
\end{abstract}

${ }^{*}$ Short title: Democratic Accountability

${ }^{\dagger}$ Assistant Professor, Department of Political Science, 4600 Wesley W. Posvar Hall, University of Pittsburgh, Pittsburgh, PA 15260, woon@pitt.edu

${ }^{\ddagger}$ Thanks to David Barker, Jonathan Bendor, Rui de Figueiredo, Jon Hurwitz, John Patty, and Ken Shotts for helpful comments and discussions. A previous version received Honorable Mention for the Best Experimental Paper presented at the 2010 APSA Annual Meeting from the APSA's Experimental Research Section. Previous versions were also presented at the 2010 Southern Political Science Association conference, the 2010 Midwest Political Science Association conference, and the 2010 EITM Summer Institute at UC Berkeley. Financial support is gratefully acknowledged from the University of Pittsburgh's Central Research Development Fund Small Grant Program and from the Dietrich School of Arts and Sciences Summer Faculty Research Fund. Replication data may be found at http://www.pitt.edu/ woon/data. 
How effectively can democratic institutions produce policy outcomes beneficial to its citizens when those citizens are uncertain about many aspects of politics? Many democratic theorists have argued that an informed citizenry is necessary for democracy to function effectively, but even the most well-informed citizens are often uncertain about the consequences of policy: whether an economic stimulus package will create jobs, whether massive bailouts are necessary to prevent the collapse of financial and automobile industries, or whether the best way to prevent terrorism is to fight wars in the Middle East and Central Asia. If politicians are better informed than citizens - because they possess innate policy expertise, because of institutional advantages that include large bureaucracies and access to technical expertise, or because of other informational advantages such as secret intelligence briefings - then such expertise could be harnessed to produce policy solutions better than those that citizens could produce on their own.

Representative democracy can produce desirable policy outcomes provided that politicians can be induced to act in citizens' interests. One way of doing so is to hold politicians accountable for policy outcomes, returning them to office for producing good outcomes and throwing them out for producing bad ones. In this view, elections are seen primarily as mechanisms of democratic accountability (Ferejohn 1986, Key 1966). Another way of ensuring good policies is to choose politicians who are not only wise leaders but whose interests are closely aligned with the public. That is, elections can be seen instead as mechanisms of democratic selection (Downs 1957, Fearon 1999, Manin 1997). But the latter theory of elections has a serious downside: if voters are sufficiently uncertain about, and concerned with, politicians' unobserved characteristics, then elections lead to perverse incentives for politicians to pander to public opinion (Canes-Wrone, Herron and Shotts 2001, Maskin and Tirole 2004). ${ }^{1}$ In this case, selection undermines sanctioning, and as a result, democratic institutions fail to effectively utilize expert policy judgments.

\footnotetext{
${ }^{1}$ The term "pandering" is more narrow than "responsiveness." The former means to follow public opinion when it goes against a politician's expert judgment about what is in the public's best interest. The latter simply means to follow the electorate's wishes.
} 
The degree to which perverse incentives undermine good policymaking depends on the view of elections held by voters and, more importantly, the extent to which voting behavior reflects those views. If voters focus on accountability and their behavior is retrospective, then perverse incentives will be minimized. But if voters focus on selection and their behavior is forward-looking or prospective, then incentives to pander may be severe. Whether politicians will choose to act as delegates or trustees crucially depends on how voters behave (Miller and Stokes 1963).

Using observational data to empirically distinguish between these two modes of voting behavior is fraught with methodological difficulty. ${ }^{2}$ Econometric issues aside, there is a fundamental problem in that retrospective and prospective behavior are observationally equivalent in many environments. In the laboratory, however, it is possible to differentiate between accountability and selection by creating and controlling the strategic environment such that there are conditions under which retrospective and prospective voting are distinct. To do so, I conduct an experiment that implements and tests the predictions of a game theoretic model (Fox and Shotts 2009).

Contrary to the game theoretic predictions, I find that subjects' voting behavior is consistent with a purely retrospective reward-punishment strategy regardless of the theoretical equilibrium. That is, voter choices are inconsistent with perfect Bayesian equilibrium. Although the behavior of politicians in the experiment also fails to conform to the equilibrium predictions, their choices are nevertheless consistent with optimal strategic play-they correctly anticipate voters' (non-equilibrium) behavior and choose best responses given their (correct) expectations.

I then conduct a set of additional treatments to investigate possible explanations for the departure from fully rational, forward-looking behavior. The additional experiments suggest two main reasons why voters use the traditional retrospective voting rule. First, it is a simple heuristic that is easy to implement when faced with a cognitively complex

\footnotetext{
${ }^{2}$ See, for example, Clarke and Stewart (1994), Evans and Anderson (2006), Lewis-Beck, Nadeau and Elias (2008), Mackuen, Erikson and Stimson (1992), Nadeau and Lewis-Beck (2001).
} 
Bayesian inference and expected utility maximization problem. ${ }^{3}$ In addition, the heuristic is reinforced by the presence of strategically irrelevant information. Second, not all voters focus purely on selection but some instead have a preference for accountability in that they are motivated to sanction politicians for their performance in office even at the cost of forgoing future expected benefits.

\section{Theory}

If voters behave according to the traditional theory of retrospective voting - rewarding politicians for producing good outcomes and punishing them for producing poor ones (Key 1966) then politicians can, in principle, be induced to take actions that benefit the public (Banks and Sundaram 1993, Ferejohn 1986). But the traditional theory of retrospective voting is not fully compatible with the rational choice view of voting behavior (Fiorina 1981), especially when voters face a second type of uncertainty about politicians' unobserved characteristics (such as their motivation, ideological leanings, or level of competence) and those characteristics affect future policy choices. Rational voters are forward-looking, so their intention is not to sanction or reward politicians' past behavior, but rather to select politicians who have desirable characteristics (Ashworth and Bueno de Mesquita 2008, Fearon 1999, Gordon, Huber and Landa 2007). To the extent that rational voters look to the past at all, it is only to form judgments about politicians' chances of producing good policies in the future (Downs 1957, Fiorina 1981, Mackuen, Erikson and Stimson 1992). ${ }^{4}$

The distinction between purely retrospective and forward-looking voting behavior can be subtle, but it has important consequences for the incentives of politicians. If voters focus on sanctioning, they induce politicians to choose policies they believe to be best for

\footnotetext{
${ }^{3}$ See Bendor, Kumar and Siegel (2010) for a formal model of bounded rationality that implies retrospective voting.

${ }^{4}$ I use the terms "forward-looking," "prospective," and "sequentially rational" equivalently. Note that the term "rational retrospective voting" is actually a form of prospective voting (because voters care about future outcomes). I will refer to "traditional" or "purely" retrospective voting to refer to behavior that ignores considerations about the future.
} 
voters, but if voters focus on selection, they instead induce politicians to demonstrate to voters that they are "good types" even if that means ignoring their expertise and choosing policies they know to be detrimental to the public interest. Following this basic logic, a variety of formal models demonstrate that there are many conditions under which elections or reputational concerns provide perverse incentives for pandering (Canes-Wrone, Herron and Shotts 2001, Fox 2007, Fox and Shotts 2009, Maskin and Tirole 2004, Stasavage 2004). The models show that dual sources of asymmetric information combine to produce a problem of accountability for rational voters: politicians have better policy information, which they can use to benefit voters, but they fail to do so because forward-looking voters reward them more for demonstrating they are good types than for producing good policies. ${ }^{5}$

The experiment implements a game of incomplete information that focuses attention on the strategic interaction between a politician, who makes policy decisions, and a voter, who decides on the politician's electoral fate (Fox and Shotts 2009). ${ }^{6}$ To summarize the game, an incumbent politician first receives a signal about an uncertain state of the world and chooses a policy. Politicians privately know their own types and are also better informed than voters about policy consequences. Voters observe the policy choice and whether or not the choice was beneficial, which allows them to learn something about the politicians' preferences and level of expertise, and then they choose whether to re-elect the incumbent or elect a challenger. The winner of the election then makes a second policy choice and the game ends. Depending on their type, politicians care about policy or re-election while voters care about the pre-election and post-election policy choices.

Game theory predicts two types of equilibria, one in which retrospective voting is

\footnotetext{
${ }^{5}$ Fox and Shotts (2009) call this a "delegate trap" while Landa (2010) calls it an "accountability trap."

${ }^{6}$ The game has a structure similar to Canes-Wrone, Herron and Shotts (2001) and Fox (2007). There are several reasons why the Fox and Shotts (2009) model is appropriate for an experimental investigation. First, the model identifies conditions under which retrospective voting is observationally equivalent to selection and conditions when it is not. The experiment can therefore test whether voting behavior varies with the conditions predicted by the model. Second, there are some conditions under which both equilibria exist. The experiment can also investigate which type of equilibrium is focal (more likely to arise in actual play). Third, in contrast to a model such as Canes-Wrone, Herron and Shotts (2001), the decision problem for politicians in Fox and Shotts (2009) is fairly simple and intuitive. This enhances the external validity of the experiment and allows the analysis to focus on the behavior of voters.
} 
observationally equivalent to forward-looking behavior (because voters learn more about politicians' expertise than they do about their preference congruence) and one in which it is not (because voters learn more about politicians' congruence than about their expertise). In the latter equilibrium, voters condition their behavior only on the politician's policy choice but not whether the policy choice was beneficial. This leads politicians to ignore their expertise and pander to voters.

\section{The Game}

The sequence of actions in the game is as follows:

1. Nature chooses a state of the world, $\omega$, which is either $A$ or $B$, where $\operatorname{Pr}(A)=\alpha>$ $\operatorname{Pr}(B)$

2. Nature chooses the politician's type, $t$ (described further below), and the type for the challenger, $c$.

3. The politician observes $t$ and a signal, $s$, about the state and chooses a policy, $p$, from $A$ or $B$.

4. The voter observes $p$ and $\omega$ and chooses whether to elect the incumbent $(v=t)$ or the challenger $(v=c)$.

5. Nature draws a new state $\omega^{\prime}$, the winner of the election observes a new signal $s^{\prime}$ and chooses a new policy $p^{\prime}$.

The politician's type is defined by a triple of three attributes, $t=\left(t_{M}, t_{P}, t_{Q}\right)$ where $t_{M}$ is motivation, $t_{P}$ is policy preference, and $t_{Q}$ is quality. Each attribute has two possible values. Motivation may be either office-seeking $\left(t_{M}=M_{O}\right)$ or policy-seeking $\left(t_{M}=M_{P}\right)$. Policy preference may be either pragmatic $\left(t_{P}=P_{P}\right)$ or ideological $\left(t_{p}=P_{I}\right)$. Quality refers to the accuracy of the politician's information about the state of the world and is either perfect $\left(t_{Q}=Q_{P}\right)$ or noisy $\left(t_{Q}=Q_{N}\right)$. Let the distribution of each attribute be described 
by $\pi_{M}=\operatorname{Pr}\left(t_{M}=M_{O}\right), \pi_{P}=\operatorname{Pr}\left(t_{P}=P_{P}\right)$, and $\pi_{Q}=\operatorname{Pr}\left(t_{Q}=Q_{P}\right)$. The probabilities for each attribute are assumed to be independent. If the voter elects the challenger, the challenger's attributes are drawn from the same distribution.

In general, the politician's utility function takes on two values, $x>0$ for "desirable" outcomes and 0 for "undesirable" outcomes, and depends on the type as follows. An officemotivated politician prefers to be re-elected (regardless of the other attributes). A policymotivated politician's preference depends on the policy preference attribute, policy choice, and possibly the state. More specifically, policy-motivated politicians who are ideological always prefer to choose policy $p=B$; policy-motivated politicians who are pragmatic prefer to match the policy to the state $(p=\omega)$.

In addition, following Fox and Shotts (2009), politicians' preferences are assumed to be lexicographic. That is, policy-motivated politicians care first and foremost about their pre-election policy choice so that considerations of post-election policy have no effect on their pre-election behavior. ${ }^{7}$ For office-motivated politicians, lexicographic preferences mean that if they are re-elected, their preferences over post-election policy depend on their policy preference attribute. $^{8}$

In each period, the accuracy of the signal the politician receives depends on the quality attribute. Politicians with perfect information receive a completely accurate signal while politicians with noisy information receive an imperfect but informative signal. Formally, $\operatorname{Pr}\left(s=\omega \mid t_{Q}=Q_{P}\right)=1$ and $\operatorname{Pr}\left(s=\omega \mid t_{Q}=Q_{N}\right)=\gamma$. The assumption that $\gamma>\alpha>1 / 2$ ensures that all politicians are better informed than voters.

Voters want politicians to choose policies that match the state of the world both before $(p=\omega)$ and after $\left(p^{\prime}=\omega^{\prime}\right)$ the election. For each policy that matches the state the

\footnotetext{
${ }^{7}$ An alternative specification of such preferences is to suppose that politicians weight pre-election policies much more heavily than post-election policies as if their time preferences were such that they are very impatient.

${ }^{8}$ Fox and Shotts (2009) also assume that there is some probability that the second period policy issue is one of "common value." This assumption ensures that ideological types will sometimes want to match the policy to the state, but it is not necessary for the equilibria they describe. I therefore omit the assumption in order to simplify the game.
} 
voter receives utility $y>0$ and otherwise receives utility 0 .

\section{Equilibrium Predictions and Hypotheses}

Fully rational behavior in this setting, which involves incomplete information, is described by the concept of perfect Bayesian equilibrium and there are two types of pure strategy perfect Bayesian equilibria in this game. ${ }^{9}$ Following Edmund Burke's classic typology of representation, there is a trustee equilibrium where voters induce office-motivated politicians to use (and therefore signal) their expertise to act in voters' best interest. There is also a delegate equilibrium in which voters induce office-motivated politicians to ignore their information and pander to voters (by choosing the same policy the voter would have chosen directly) in order to signal their preference alignment with voters and win re-election. It is important to note that because perfect Bayesian equilibrium assumes that voters are sequentially rational, voters in both types of equilibria are necessarily prospective and forward-looking. This means that voter behavior in the trustee equilibrium is observationally equivalent to a retrospective (sanctioning) rule, but in the delegate equilibrium, retrospective and prospective behavior are distinct.

In both types of equilibria, pragmatic types maximize the probability of choosing $p=\omega$ while ideological types only benefit if $p=B$. (The strategies of policy-motivated politicians are the same in both equilibria because their payoffs do not depend on the voter's action due to the lexicographic nature of their preferences.) This implies the following prediction about policy-motivated politicians' behavior.

Hypothesis 1 For any parameterization of the game, politicians who are policy-motivated and pragmatic will follow their signals and choose $p=s$ while politicians who are policymotivated and ideological will always choose $p=B$.

In either type of equilibrium, the strategies of office-motivated politicians and voters are mutually dependent. To understand the logic of the strategic interaction between

\footnotetext{
${ }^{9}$ See Fox and Shotts (2009) for detailed statements of the equilibria and their proofs.
} 
office-motivated politicians and voters, first note that an office-motivated politician's optimal policy choice will depend critically on the voter's decision rule. If the electoral reward is for outcomes (as in the trustee equilibrium), then they maximize the probability of re-election by choosing the policy to match the signal. If the electoral reward is instead for policy choices (as in the delegate equilibrium), then re-election is guaranteed when $p=A$.

The basic principle underlying the voter's decision is sequential rationality. Rational voters will re-elect the incumbent if and only if they believe the incumbent is more likely to choose a good policy than would a randomly drawn challenger. ${ }^{10}$ While the general rule is intuitive, the details of the calculation are more complicated and involve two factors: preferences over politicians' types (the probability that each type of politician will match the policy to the state in the second period) and the voter's updated beliefs about the incumbent's type. Because the motivation attribute $\left(t_{M}\right)$ has no effect on politicians' postelection policy choices, voters care only about the preference $\left(t_{P}\right)$ and quality $\left(t_{Q}\right)$ attributes of the candidate they elect for the second period.

Although there are eight possible types of politicians, from the voter's perspective they can be grouped into three effective types. Of these, the best type of politicianin terms of the likelihood of choosing good future policies - is one who is pragmatic with perfect information $\left(P_{P}, Q_{P}\right)$ because they will match the policy to the state with certainty. Pragmatic politicians with noisy information $\left(P_{P}, Q_{N}\right)$ are second best since they are the second-most likely type to match the policy to the state (which occurs when their signals are correct with probability $\gamma<1)$. The worst types are ideological politicians $\left(P_{I}, Q_{N}\right.$ or $Q_{P}$ ), who are the least likely to match the policy to the state (which occurs only when the state is $B$ with probability $1-\alpha<\gamma)$.

The final and most critical step in the voter's calculation is to make correct inferences

\footnotetext{
${ }^{10}$ Formally, this holds if

$$
\frac{q_{P P}(p, \omega)+q_{P N}(p, \omega) \gamma+q_{I}(p, \omega)(1-\alpha)}{\pi_{p} \pi_{q}+\pi_{p}\left(1-\pi_{q}\right) \gamma+\left(1-\pi_{p}\right)(1-\alpha)} \geq 1,
$$

where $q_{T}(p, \omega)$ denotes the posterior belief that the incumbent is type $T \in\{P P, P N, I\}$ where $P P$ is pragmatic perfect, $P N$ is pragmatic noisy, and $I$ is ideological.
} 
about the politician's type using Bayes' Rule, knowledge of the initial distribution of types, and expectations of politicians' strategies. A key tension exists between the voter's belief that the incumbent may be a pragmatic, perfectly informed politician (the best type) or an ideological type (the worst type). When the voter learns that the state is $A$, these beliefs both move in directions that point unambiguously to one of the candidates. If $p=A$ and $\omega=A$ the incumbent is both more likely to be the best type and less likely to be the worst type, so it is best to re-elect the incumbent. And if $p=B$ and $\omega=A$ the incumbent is both less likely to be the best type and more likely to be the worst type, so it is best to elect the challenger. Whenever the state is $B$, however, beliefs move in directions that make the voter's choice more difficult. That is, if $p=B$ and $\omega=B$ then the incumbent is more likely to be pragmatic with perfect information but also more likely to be ideological. Similarly, if $p=A$ and $\omega=B$ then the incumbent is less likely to be the best type but also less likely to be the worst type.

The type of equilibrium reflects the way in which this trade-off between types is resolved. In a trustee equilibrium the voter learns enough about the politician's quality to outweigh any concerns about the likelihood the politician is ideological. In this case, an outcome-based voting rule is best: re-elect the politician if and only if $p=\omega$. Conversely, in a delegate equilibrium the voter learns enough about the politician's preference that considerations about quality are set aside. In this case, the voter infers from observing $p=A$ that the incumbent is much less likely to be ideological than the challenger (even if the challenger might be more likely to have perfect information). Thus, in a delegate equilibrium, a policy-based voting rule is optimal: re-elect the politician if and only if $p=A$. The following hypotheses summarize the equilibrium predictions about the behavior of voters and office-motivated politicians in terms of their dependence on $\pi_{Q}$.

Hypothesis 2 If the prior probability that politicians have perfect information $\left(\pi_{Q}\right)$ is sufficiently high, then in a trustee equilibrium office-motivated politicians will follow their signals $(p=s)$ while voters will use an outcome-based rule and re-elect incumbents if and only if 
the policy matches the state $(p=\omega)$.

Hypothesis 3 If the prior probability that politicians have perfect information $\left(\pi_{Q}\right)$ is sufficiently low, then in a delegate equilibrium office-motivated politicians will always pander $(p=A)$ while voters will use a policy-based rule and re-elect incumbents if and only if the policy is $A$. If $\pi_{Q}$ is extremely low, then this will be the only behavior observed.

For some values of $\pi_{Q}$, there are multiple equilibria so that these hypotheses are not mutually exclusive. This is because when $\pi_{Q}$ is in a middle range, it is sufficiently high for a trustee equilibrium as well as sufficiently low for a delegate equilibrium. As stated in Hypothesis 3, however, game theory makes a unique prediction when $\pi_{Q}$ is especially low. ${ }^{11}$ Because the type of equilibrium depends on $\pi_{Q}$, a comparative static prediction follows as a corollary of Hypotheses 2 and 3 .

Hypothesis 4 If the prior probability that politicians have perfect information decreases, then delegate equilibrium behavior is more likely; office-motivated politicians will be more likely to choose $p=A$ and voters will be more likely to re-elect incumbents when $p=A$.

It is important to reiterate that although the voter's decision rule is observationally equivalent to a sanctioning rule in the trustee equilibrium and observationally equivalent to a selection rule in the delegate equilibrium, voters actually focus on selection in both types of equilibria (because they are assumed to be forward-looking). The difference between motivations for using the outcome-based decision rule in the trustee equilibrium and a true retrospective punishment-reward rule cannot be overemphasized. When voters use the outcome-based rule in the trustee equilibrium, they do so only because they want to elect

\footnotetext{
${ }^{11}$ When $\pi_{Q}$ is extremely high, the trustee equilibrium is also unique, but the experiment is not designed to test conditions when the trustee equilibrium is unique. The key to understanding why the equilibrium is sometimes unique is that when the prior probability $\pi_{Q}$ is extreme, the voter will update beliefs such that only one type of voting rule is a best response. That is, when $\pi_{Q}$ is extremely low, the policy-based rule is a best response regardless of whether the politician followed signals or always chooses $p=A$. When $\pi_{Q}$ is extremely high, the outcome-based rule is a best response regardless of whether the politician follows signals or always chooses $p=A$.
} 
higher quality politicians and infer that when the policy matches the state, the incumbent is indeed more likely to be higher quality (that is, more likely to have perfect information). In contrast, voters will use the purely retrospective voting strategy when they want to induce good policy above all else - even at the cost of lower future expected utility from electing a bad type.

\section{Baseline Experiment}

\section{Procedures}

The baseline experiment implements the accountability model in the laboratory to test whether behavior is consistent with game theoretic predictions. ${ }^{12}$ All experiments were conducted at the Pittsburgh Experimental Economics Laboratory at the University of Pittsburgh. In the baseline experiments, 88 subjects participated in 5 separate sessions, each session consisted of between 14 and 20 subjects, and each subject participated in only one session. All subjects were recruited through the lab's centralized database. ${ }^{13}$

Upon arriving at the lab, subjects gave informed consent and were seated at separate computer terminals. All interactions between subjects took place anonymously through the networked computers using software programmed and conducted using z-tree (Fischbacher 2007). Subjects received strict instructions not to communicate with one another in any way throughout the session. The instructions were presented on their computer screens and read aloud in order to induce common knowledge among the participants. Subjects also received a printed copy of the instructions, which they were encouraged to refer to as often as they needed, and then were given a quiz about the instructions in order to ensure comprehension. The quizzes were also administered through the computers so that subjects privately received immediate feedback about whether or not they answered the questions correctly, including

\footnotetext{
${ }^{12}$ The full text of the instructions can be found in the Supporting Information.

${ }^{13}$ Most subjects were undergraduates, although 15 participants (17\%) were graduate students, staff members, or individuals from the community who were not affiliated with a university.
} 
the explanations of the correct answers. Consistent with the lab's governance policy, no deception or false feedback was used at all in the experiment.

Each subject participated in exactly one session and played the game 36 times, 18 times as a "politician" and 18 times as a "voter." Each play of the game was described to subjects as a "round," but they were explicitly instructed that each round should be considered as a "separate decision task." Roles as politicians or voters remained fixed for 6 rounds at a time and in every round, one politician was randomly matched with one voter. In order to minimize the possibility of reputation effects, the random matching protocol ensured that the expected number of times two subjects were paired throughout the session was approximately equal for any given pair of subjects. ${ }^{14}$ Thus, some subjects switched roles after a set of 6 rounds while others remained in the same role. The matching rule also ensured that subjects would gain experience with both roles in the first 12 rounds. In order to preserve anonymity, subjects were not informed of the ID number of the subject they were paired with in any round until after all rounds of the game were played.

The subjects played a game that was strategically equivalent to the model described in the previous section. The only difference was that in the experimental game, the sequence of actions is simplified so that politicians chose only the first period policy. However, the games are isomorphic and all of the predictions hold exactly. In every round, there was a $60 \%$ probability that the state was $A\left(\alpha=\frac{3}{5}\right)$ and a $67 \%$ probability that politicians with noisy information received the correct signal $\left(\gamma=\frac{2}{3}\right)$. There was a $75 \%$ probability that politicians (both incumbents and challengers) were office-motivated $\left(\pi_{M}=\frac{3}{4}\right)$ and a $25 \%$ probability that politicians were pragmatic $\left(\pi_{P}=\frac{1}{4}\right)$. The probability that politicians had perfect information $\left(\pi_{Q}\right)$ varied by session. In two delegate-trustee sessions $(32$ subjects total), $\pi_{Q}=50 \%$ implies that there are multiple equilibria (Hypotheses 2 and 3 both apply). In three delegate sessions (56 subjects total), $\pi_{Q}=10 \%$. This value of $\pi_{Q}$ is low enough to

\footnotetext{
${ }^{14}$ The expected number of rounds was exactly equal if the number of subjects in a session was a multiple of 4 and approximately equal otherwise. A more common matching protocol in many experiments is to divide subjects into two groups and then switch roles once, but this means that subjects have a 0 probability of being matched with $(N / 2)-1$ other subjects in a session.
} 
guarantee that Hypothesis 3 is the unique prediction (that is, voters will never learn enough about the politician's quality so that the policy-based voting rule is optimal). Comparing the sessions with different values of $\pi_{Q}$ allows for a test of Hypothesis 4 (comparative statics).

To ensure that voter preferences matched the theoretical model, their payoffs are defined as the sum of a policy component and an election component. For the policy component, if the incumbent matches the policy to the state $(p=\omega)$, then the voter receives $y=150$ "tokens"; otherwise, the voter receives 0 tokens from the policy choice. For the election component, electing a pragmatic politician with perfect information gives the voter 150 tokens, electing a pragmatic politician with noisy information gives the voter 100 tokens, and electing an ideological type gives the voter 60 tokens. ${ }^{15}$ Thus, the minimum payoff in any round is 60 (when the policy does not match the state and the voter elects an ideological type) and the maximum payoff is 300 (when the policy matches the state and the voter elects a pragmatic perfect type). For politicians, the payoffs are $x=150$ "tokens" for desirable outcomes (according to their type) or 0 "tokens."

Because the purpose of the experiment is to test voting behavior rather than to test abstract strategic thinking, the language used to describe and implement the game involved a moderate degree of natural and descriptive (but neutral) political context, rather than the abstract language typically used in game theory experiments. The two roles for subjects are described as those of "politicians" and "voters." Politicians' attributes are described as their "motivation," "preference," and "quality of information." The pairs of attribute values are "office-seeking" or "policy-seeking," "pragmatic" or "ideological," and "perfect" or "noisy," respectively. ${ }^{16}$ States, signals, and policy choices are described in terms of policies "A" or "B." Finally, voters either "re-elect the politician" or "elect the challenger."

\footnotetext{
${ }^{15}$ These are the expected values of electing each type if correctly matching $p^{\prime}=\omega^{\prime}$ yields a payoff of 150 tokens. Pragmatic perfect types do so with probability 1, pragmatic noisy types do so with probability $67 \%$ (the probability of receiving a correct signal), and ideological types do so with probability $40 \%$ (the probability that the state is $B$ ).

${ }^{16}$ The language used in the experiments differs from the presentation of Fox and Shotts (2009), who use terms that are potentially more value-laden. They use the terms "ambitious" and "unambitious" for motivation, "congruent" and "noncongruent" for preference, and "skilled" and "unskilled" for quality.
} 
After every round, the computer interface provides subjects with information about the round, including the subject's own earnings from that round, the incumbent's and the challenger's attributes, the value of the true state, the politician's choice, and the voter's choice. Subjects find out only about the results of their own play of the game and do not learn the results of any games played by other pairs of subjects.

Earnings in the game were denominated in "tokens," and subjects' total earnings from all 36 rounds of the game were converted to dollars at the rate of $\$ 1$ for every 300 tokens. Thus, politicians earn $\$ 0.50$ in a single round for a "desirable" outcome (e.g., office-motivated type getting re-elected) and $\$ 0.00$ for an "undesirable" outcome; voters earn between $\$ 0.20$ and $\$ 1.00$ in each round. Earnings were paid in cash, privately, to each subject at the conclusion of the experimental session and included an additional $\$ 5$ "show-up" payment. Total cash payments ranged from $\$ 15.85$ to $\$ 25.95$ with an average of payment of $\$ 21.81$.

The use of real-world context is not typical of game theoretic experiments, so its use warrants further consideration. Most experimental tests of game theoretic predictions use abstract "context-free" language for describing the decision tasks to subjects such as labeling the players as 1 and 2 rather than as a "politician" and a "voter." This is often because the mathematical structure of the games is deemed the most relevant for choice behavior. The actual labels are thought to be strategically irrelevant, and the use of context is sometimes thought to imply a lack of experimental control.

But there are several reasons why context is not only appropriate, but also desirable. First, Hertwig and Ortmann (2001) argue that the key to experimental control is the use of a script (careful instructions that fully describe the game) and that such scripts may or may not involve context. Second, the use of real-world context provides clues to help subjects recognize and interpret the game and allows them to draw on their previous experience in similar settings. Indeed, Loewenstein (1999) argues that "the context-free experiment is. . an elusive goal" - an abstract setting is simply an unfamiliar context - and that "the goal of external validity is served by creating a context that is similar to the one in which...agents 
will actually operate" (F30-F31). ${ }^{17}$ Similarly, experiments with signaling games, which are games of incomplete information like the ones in this paper, have shown that context increases the initial level of strategic play and acts as a substitute for experience (Cooper and Kagel 2003). Chou, McConnell, Nagel and Plott (2009) also suggest that context leads to greater experimental control because it enables subjects to recognize the game as the experimenter intends. Thus, the use of context is not only consistent with experimental practice but also enhances internal as well as external validity.

\section{Results}

The upper two panels of Figure 1 show that when subjects play the role of policy-motivated politicians their choices conform to the equilibrium predictions, thus providing strong support for Hypothesis 1. Across all sessions in the baseline experiment, 95\% of pragmatic types chose policy $A$ when the signal was $A$ and only $17 \%$ chose policy $A$ when the signal was B. Overall, $90 \%$ of pragmatic politicians' choices were consistent with rational expected utility maximizing behavior (following their signals). Similarly, ideological types chose $p=$ $A$ in only $15 \%$ ( $p=B$ in $85 \%$ ) of their opportunities. Note that although the decision problem for policy-motivated politicians is non-strategic, as their payoffs do not depend on the voter's choice, their behavior nevertheless plays an important role in the inferences that fully rational, Bayesian voters make about the incumbent's type. These results reassure us that simple incentives guide behavior in the way that rational choice predicts and that an important source of voters' equilibrium beliefs is consistent with the theoretical prediction.

[Figure 1 about here.]

The lower panel of Figure 1 shows that office-motivated politicians generally follow their signals. When they receive the signal $A$, they overwhelmingly chose $p=A$ in $95 \%$

\footnotetext{
${ }^{17}$ An example where context improves decision-making is Wason's classic "four-card problem" (Wason and Shapiro 1971). When it is presented in the abstract, subjects make logically correct choices only about $10 \%$ of the time. However, when a logically equivalent problem is presented using a familiar context, the proportion of correct choices improves dramatically, to about 70\% (Chrostowski and Griggs 1985) in one context and to about $89 \%$ in another (Cosmides 1989).
} 
of chances in the delegate-trustee sessions and $90 \%$ in the delegate sessions. Since $p=A$ when $s=A$ is consistent with both types of equilibrium strategies, this result is consistent with both Hypotheses 2 and 3. The more discriminating situation is when $s=B$, where the two types of equilibrium strategies prescribe different behavior ( $p=A$ for pandering and $p=B$ for following signals). In all sessions, subjects only chose policy $A$ in $20 \%$ of their chances (19\% in delegate only and $23 \%$ in delegate-trustee sessions). Thus, instead of pandering, office-motivated politicians generally followed their signals (85\% in delegate sessions and $87 \%$ in the delegate-trustee sessions). In the delegate-trustee sessions, this behavior is consistent with Hypothesis 2. But in the delegate only sessions, the observed behavior is clearly inconsistent with the equilibrium prediction in Hypothesis 3. Such behavior may nevertheless be consistent with optimal strategic play - that is, it is a best response if voters always use an outcome-based voting rule.

[Figure 2 about here.]

Voting behavior is shown in Figure 2, and the results strongly suggest that voters indeed used an outcome-based rule in both types of sessions. Voters re-elected politicians when policies matched the state $95 \%$ of the time when $p=\omega=A$ and $87 \%$ of the time when $p=\omega=B$. In contrast, when politicians chose a policy different from the state, voters re-elected them at much lower rates: in $35 \%$ of all cases when $p=A$ and $\omega=B$ and in $16 \%$ of cases when $p=B$ and $\omega=A$. While the observed outcome-based voting rule is consistent with the trustee equilibrium (Hypothesis 2) in the delegate-trustee sessions, it is clearly inconsistent with the unique equilibrium prediction (Hypothesis 3) for the delegate sessions. Thus, both politicians' and voters' choices are consistent with game theoretic predictions in the delegate-trustee sessions but not the delegate only sessions. ${ }^{18}$

Even though there is no support for the delegate equilibrium point prediction (Hypothesis 3), is there any evidence to support the comparative static prediction that delegate

\footnotetext{
${ }^{18}$ See the Supporting Information for figures showing the distribution of subject-level retrospective voting behavior, which reinforce the aggregate-level results.
} 
equilibrium behavior is more likely in the delegate session than in the delegate-trustee sessions (Hypothesis 4)? According to Hypothesis 4, politicians should be less likely to follow their signals in the delegate sessions, but we cannot reject the null hypothesis of no difference in behavior ( $p=0.24$, one-tailed). In addition, voters should be less likely to use a retrospective (outcome-based) voting rule, but neither can we reject the null hypothesis of no difference in voter behavior ( $p=0.56$, one-tailed). Thus, there is no evidence that the distribution of politicians' quality $\left(\pi_{Q}\right)$ affects behavior in the manner predicted by the theory. The remarkable consistency across the two types of sessions, especially of voter behavior, suggests that the equilibrium-consistent behavior observed in the delegate-trustee session may not have been because subjects properly deduced their best responses, which is one interpretation of Nash equilibrium theory.

[Table 1 about here.]

But Nash equilibrium theory does not necessarily require equilibrium play to come about purely by introspection. Instead, it can be interpreted as describing stable outcomes. That is, since non-equilibrium behavior is unstable (by definition), observed play should evolve over time towards the equilibrium, especially when the equilibrium is unique. The experimental data suggest otherwise. In the upper part of Table 1, the data are split into the initial and later periods when a subject makes choices as each type of politician. There are only two statistically significant differences in behavior. First, subjects are more likely to choose $p=B$ in later periods than in their initial period as an ideological type. Second, they are more likely to choose $p=A$ in later periods as office-motivated politicians in the delegate sessions. While this may seem to suggest adaptation towards equilibrium behavior, the data also show that they are more, rather than less, likely to follow their signals, which is inconsistent with learning to play the equilibrium. In addition to showing the differences between initial and subsequent periods, Table 1 also reports trend coefficients from probit models with experience (number of previous rounds at the information set) as the indepen- 
dent variable. The probit estimates reinforce the conclusion that little or no learning takes place over time.

Voter behavior over time is shown in the lower part of Table 1, which similarly divides

choices into the initial and later periods for each information set and shows the estimated time trends. Across both the delegate and the delegate-trustee sessions and at every information set, initial and overall choices throughout the experiment are statistically indistinguishable. The time trend estimates also show that there was no gradual adjustment of behavior over time. Thus, there is no evidence whatsoever that subjects adapted or learned to play the equilibrium. Instead, there is a stable behavioral tendency for voters to first use an outcomebased voting rule and for them to adhere to the rule throughout the experimental sessions.

\section{Discussion}

Is it possible to pinpoint the source of non-equilibrium behavior? That is, Perfect Bayesian equilibrium reflects a package of rationality assumptions. To what extent is behavior consistent with basic principles of rational choice, to what extent is it optimally strategic, and to what extent do subjects make correct inferences from the information they receive? Clearly, some observed behavior is consistent with rational expected utility maximization. The most obvious is the behavior of policy-motivated politicians. Their decision problem is non-strategic, and subjects' choices in the experimental sessions were generally consistent with their simple incentive structure (Hypothesis 1), albeit with some noise.

In contrast to the decision problem of policy-motivated politicians, the problem faced by office-motivated politicians is strategic. The best response for office-motivated politicians is a function of how they anticipate voters will react. If subjects anticipate that they will be re-elected for choosing policy $A$, then the optimal action is to choose $A$. If they anticipate re-election for choosing correct policies, then it is optimal to follow their signals. Although subjects' choices as office-motivated politicians were inconsistent with equilibrium predictions (Hypothesis 3), their choices were in fact best responses to the outcome-based strategy 
actually employed by voters. The data therefore provide evidence that subjects were able to think strategically and to rationally anticipate how others would respond to the choices they made. Moreover, the fact that there was no distinction between initial and subsequent choices suggests that politicians chose best responses as the result of introspection (thinking about the game) rather than through learning and adaptation.

The principal source of non-equilibrium behavior therefore appears to be the voters' decision-making process. Even though politicians followed their signals in the delegate sessions, sequentially rational Bayesian voters would have maximized their expected utility by re-electing the incumbent whenever $p=A$ and electing the challenger when $p=B$. Because there always exist beliefs such that retrospective voting is a best response, the data do not necessarily violate the sequential rationality assumption. ${ }^{19}$ Nevertheless, retrospective voting is a best response for voters in the experiment only if their beliefs are mistaken. More specifically, the policy-based voting rule is a best response regardless of whether voters believed (e.g., through introspection) that office-motivated politicians follow their signals with probability 1 or if voters' correctly inferred beliefs from the empirical frequencies of politicians' choices. ${ }^{20}$ The data from the baseline experiment therefore suggest that voters failed to use a policy-based voting rule because they may have failed to correctly form beliefs about the incumbent's type.

Although subjects' choices were neither consistent with equilibrium strategies nor with best responses to politicians' empirical play, they were rather decisive. As noted above, they overwhelmingly re-elected politicians who chose policies that matched the state, and there was a clear tendency to elect the challenger otherwise. The level of decisiveness which voters displayed suggests that one common approach to explaining departures from equilibrium, the quantal response equilibrium (QRE) concept of McKelvey and Palfrey $(1995,1998)$,

\footnotetext{
${ }^{19}$ A trivial, but implausible, example of such beliefs would be that the politician is policy-motivated and pragmatic with perfect information with probability 1 when $p=\omega$ and is ideological with probability 1 when $p \neq \omega$. Other, more plausible, beliefs exist as well, such as the posterior beliefs in any trustee equilibrium.

${ }^{20}$ For the empirical distributions of politicians' payoff-relevant types and the computation of expected payoffs for each voter information set, see the Supplemental Information.
} 
may not be useful in this context. Nevertheless, it is worth considering the possibility because QRE does help to account for observed behavior in many games. The main idea of QRE is to allow for players' best responses to be "noisy" rather than deterministic, but although it allows for "mistakes," it retains the notion of equilibrium - that is players' probabilistic choices are best responses to others' probabilistic best responses. In the logit AQRE, when $\omega=B$, the probability of re-electing the incumbent when $p=A$ is always greater than the probability of re-electing the incumbent when $p=B .^{21}$ This implies that even noisy best responses are insufficient to cause voting behavior to approximate an outcome-based or retrospective voting strategy. Thus, the results of the baseline experiment appear to be inconsistent with both perfect Bayesian equilibrium and quantal response equilibrium. The reason for this may be that both equilibrium concepts require beliefs to be consistent with Bayes' Rule.

\section{Bounded Rationality}

To investigate possible explanations for retrospective voting behavior, I designed and conducted additional experimental treatments. One possible explanation is the cognitive complexity of the decision problem (Simon 1955): voters fail to make optimal decisions because the Bayesian inference and expected utility maximization problems they face are too difficult. Several treatments test this explanation. The policy information (PI) and information choice (IC) treatments investigate whether the presence of irrelevant information leads voters use an inferential shortcut while the simplified type (ST) treatment tests whether reducing the complexity of the decision problem reduces reliance on the retrospective voting rule. Another possible explanation is that there is a norm or preference for accountability: voters use a retrospective strategy because they recognize that doing so induces politicians to utilize their information. This is also a form of bounded rationality because it fails to recognize the

\footnotetext{
${ }^{21}$ I computed the logit AQRE using GAMBIT version 0.2007.01.30 (McKelvey, McLennan and Turocy 2007). A figure showing the voter's QRE choice probabilities can be found in the Supporting Information.
} 
importance of selection incentives and therefore involves an error in reasoning. The forward payoff (FP) treatment explores the latter possibility.

In each of the additional treatments, subjects play a modified version of the baseline game in which the hypothesized source of non-equilibrium behavior is removed. The game theoretic predictions for voter behavior in all of the modified games are equivalent to the delegate equilibrium prediction in which voters optimally use a policy-based voting rule, so game theory provides the basis for the null hypothesis of no difference between the baseline and additional treatments. But if the behavioral hypotheses about the sources of retrospective behavior have merit, then voters will make choices consistent with the equilibrium more frequently in the additional treatments than voters did in the baseline experiment.

\section{Strategic Irrelevance: Policy Information and Information Choice Treatments}

In the delegate equilibrium, the optimal policy-based voting rule is to re-elect the incumbent if and only if the incumbent chooses $p=A$, regardless of the observed value of $\omega$. Knowledge of $\omega$ is therefore irrelevant. But if voters are unable to make valid inferences about the relative probabilities of different types of politicians, they may not recognize this fact. Instead, if they are forward-looking, they might reason that because matching the policy to the state is a good outcome, good types are more likely to have produced good outcomes than bad types. This line of reasoning may be stimulated by the mere presence of information about the state. That is, voters may be unable to ignore strategically irrelevant information (Healy, Malhotra and Mo 2010), just as individuals are unable to ignore irrelevant information in forming evaluations and judgments in many other situations: e.g., "hindsight bias" (Fischhoff 1975), "outcome bias" (Baron and Hershey 1988), and the "curse of knowledge" (Camerer, Loewenstein and Weber 1989).

To test this possibility, I designed two treatments. The policy information treatment exogenously removes strategically irrelevant information and is identical to the delegate 
sessions of the baseline experiment except that voters only observe the policy $p$ and do not observe the state $\omega$. Note that because the politician's incentives are identical to the baseline, the voter's inference problem is identical to the baseline. However, if subjects condition their vote on the only information available to them (the policy choice), I expect that they are more likely to use a policy-based voting rule than in the baseline.

The presence of strategically irrelevant information is endogenous in the information choice treatment, which measures the extent to which voters (mistakenly) think that additional information is useful. In the IC treatment, voters first observe only the policy $p$, like in the PI treatment, but also choose whether or not to acquire information about the state by paying a small fee of 10 tokens before making a vote choice. In the perfect Bayesian equilibrium, voters would forgo acquiring information and use a policy-based voting rule. I expect that subjects who are deterred by the information cost are more likely to use a policy-based rule than in the baseline. On the other hand, if a subject believes that having more information is better and is willing to pay a small cost for it, then I expect those subjects to use the same outcome-based voting rule they use in the baseline experiment.

There were 36 subjects who participated in two sessions of the PI treatment and 30 subjects who participated in two sessions of the IC treatment. ${ }^{22}$ Table 2 compares the voting behavior of subjects in the baseline with subjects in the PI and IC treatments who only have strategically relevant information. The results show that when irrelevant information is exogenously removed in the PI treatment, subjects are more likely to use a policy-based voting rule: they are more likely to re-elect the incumbent when $p=A$ and less likely to re-elect the incumbent when $p=B$. The differences from the baseline are statistically significant, although their magnitudes are not overwhelming. In the IC treatment, where the absence of irrelevant information is endogenous, the small information cost was enough to deter most subjects (71\%) from learning about the state. These subjects were more likely

\footnotetext{
${ }^{22}$ As with the baseline experiment, each subject took part in only one session (and therefore only one treatment). Furthermore, none of the subjects in the additional treatments took part in the baseline experiment, so they had no prior experience with the game.
} 
to re-elect if $p=A$ than in the baseline, but not more likely when $p=B$. Interestingly, subjects were more willing to purchase information about the state when the policy was $B$ (35\%) than when the policy was $A(22 \%) .{ }^{23}$

[Table 2 about here.]

Table 3 shows that subjects in the IC treatment who purchased irrelevant information about the state were somewhat more likely to use an outcome-based retrospective voting rule than subjects in the baseline experiment. When the policy was $A$ and correctly matched the state, subjects re-elected politicians at every opportunity they had to do so (i.e., a $100 \%$ re-election rate). Conversely, when the policy was $A$ but did not match the state, voters never re-elected the incumbent. When the policy was $B$ and correctly matched the state, the re-election rate was $96 \%$ and when the policy did not match the state, the re-election rate was $13 \%$.

[Table 3 about here.]

The results of the PI and IC treatments indicate that the use of irrelevant information is partly responsible for retrospective voting, but that removing such information is not sufficient to induce subjects to use the optimal policy-based voting rule. This suggests that other features of the inference problem may still pose a challenge for voters.

\section{Cognitive Complexity: Simplified Type Treatment}

In the baseline experiment, there are eight possible types of politicians but they take only two possible actions, so perfect separation of politician types is not possible. Applying Bayes' Rule in this situation is neither straightforward nor intuitive. The simplified type treatment investigates whether the difficulty of the decision task is a factor that helps explain behavior (Kotovsky, Hayes and Simon 1985, Simon 1990).

\footnotetext{
${ }^{23}$ The difference was statistically significant ( $p=0.001$, two-tailed).
} 
The ST treatment simplifies the type space by reducing it to two types: politicians are either pragmatic or ideological, with each type equally likely. There is perfect correlation between the motivation and preference attributes so that pragmatic politicians are all office-seeking and ideological politicians are all policy-seeking, and both types have noisy information. ${ }^{24}$ All other parameters remained the same as in the baseline experiment so that voters received 100 tokens from electing a pragmatic type and 60 tokens from electing the ideological type (in addition to 150 tokens if $p=\omega$ ).

In the ST treatment, a delegate equilibrium exists. To see why, note that if pragmatic politicians always choose $p=A$ and ideological politicians always choose $p=B$, then voters can perfectly infer the politician's type from observing the policy choice. It is therefore sequentially rational to use a policy-based voting rule and for pragmatic (office-motivated) politicians to always choose $p=A$.

However, no trustee equilibrium exists for any parameters of the ST treatment. To see why, suppose that pragmatic politicians follow their signals while ideological types choose $p=B$. Because politicians' information about $\omega$ is always noisy, there is some probability that $p=A$ and $\omega=B$. When voters observe this, they infer (with certainty) that the politician must be a pragmatic type, as ideological types never choose $p=A$. The voters' best response is therefore to use the policy-based voting rule. ${ }^{25}$ But then if the voter uses a policy-based rule, an office-motivated politician who observes the signal $B$ will deviate to choosing policy $A$ (which guarantees re-election) rather than following the signal and choosing policy $B$ (which does not).

By reducing the type space, the voter's Bayesian inference problem is much more manageable. It certainly does not require complicated numerical weighting of relative probabilities. However, understanding the equilibrium in the ST treatment still requires a degree

\footnotetext{
${ }^{24}$ Substantively, it seems reasonable to assume that ideologues would care more about implementing their favorite policies than holding office while power-hungry politicos might choose correct policies, so encountering this setup would not violate subjects' real-world beliefs about politics. Regardless of the substantive justification, however, the assumed correlation between motivation and preference is necessary to ensure a delegate equilibrium.

${ }^{25}$ Note that this is true regardless of whether politicians always choose $A$ or follow their signals.
} 
of strategic sophistication because arriving at the correct posterior beliefs requires an understanding of politicians' incentives. Nevertheless, because the complexity of the decision problem is reduced, voter choices in the ST treatment should be closer to the equilibrium predictions than in the baseline experiment.

Figure 3 compares voting behavior in the ST treatment (two sessions with a total of 30 subjects) with the pooled data from the baseline. The data clearly support the hypothesis that simplifying the type space induces behavior that is closer to equilibrium. The re-election rate when $p=A$ and $\omega=B$ nearly doubles from $35 \%$ to $71 \%(p<.001$, one tailed $)$ while the re-election rate when $p=\omega=B$ decreases from $87 \%$ to $73 \%$ ( $p<.001$, one-tailed $)$.

[Figure 3 about here.]

Consistent with the equilibrium predictions, voters tended to re-elect politicians who chose policy $A$, although their decisions continued to be affected by knowledge of the state ( $99 \%$ when $\omega=A$ but $71 \%$ when $\omega=B$ ). Subjects therefore seemed to recognize that $p=A$ and $\omega=B$ implies the incumbent must have been a pragmatic type.

However, in contrast to the equilibrium, voters also continued to re-elect politicians at a high rate when the incumbent correctly matched the policy $B$ to state $B(73 \%)$ even though they should have inferred that an ideological type was more likely to have chosen $p=B$. The application of Bayes' Rule is relatively straightforward in this setting, although voters' failure to fully conform to equilibrium behavior suggests that it is still not intuitive. ${ }^{26}$ It is unclear from the data exactly why voters continue re-elect politicians when $p=\omega=B$, but it is likely the case that voters continue to have difficulty drawing correct inferences and that they also fail to fully consider the strategic implications of politicians' actions (Patty and Weber 2007).

\footnotetext{
${ }^{26} \mathrm{It}$ is also telling that when a demonstration of the ST treatment was conducted with an audience that had a significant background in game theory, their behavior closely resembled that of laboratory subjects: $80 \%$ voted for the incumbent when $p=\omega=A, 25 \%$ when $p=A$ and $\omega=B, 10 \%$ when $p=B$ and $\omega=A$, and $75 \%$ when $p=\omega=B(N \approx 30)$. Only after they were explicitly prompted to consider beliefs weakly consistent with the politician's strategy did they recognize that the optimal voting strategy was not retrospective.
} 


\section{Preference for Accountability: Forward Payoff Treatment}

Another possible explanation for retrospective voting in the lab is that voters follow a norm or exhibit a preference for accountability: purposefully "rewarding" politicians for good outcomes and "punishing" them for bad ones. In other words, they might understand elections in terms of sanctioning and accountability and, moreover, recognize that purely retrospective voting encourages politicians to follow their signals in order to maximize the voter's policy benefits. If so, then it may be the case that voters are either unaware of selection incentives or that they recognize them but forgo selection in favor of sanctioning.

The preference for accountability implies "punishment" behavior that appears to resemble behavior in ultimatum game and collective action/public goods experiments that also violates sequential rationality (Fehr and Gächter 2000, Ostrom, Walker and Gardner 1992), but this interpretation is problematic. Ultimatum bargaining involves a division or allocation of benefits, so subjects reject low offers because such offers are essentially unfair or too selfish. Similarly, subjects in public goods games are willing to punish free-ridinganother form of selfish or opportunistic behavior. In contrast, the electoral accountability game does not involve divisible benefits, so the motives for behavior do not readily admit a fairness interpretation.

Furthermore, retrospective voting is not consistent with the interpretation that it involves "punishing" self-serving behavior while "rewarding" other-regarding behavior. To see why, suppose that office-motivated politicians always follow their signals and consider the "bad" outcome where $p=A$ and $\omega=B$. In this case, the politician cannot have been an ideological, policy-seeking type (the type that most resembles "selfish") and instead must have had inaccurate information (regardless of whether they were office or policy motivated). In this case, voters "punish" the politician not for acting selfishly, but instead for acting in the voter's best interest - that, given the politician's information, maximized the probability

of a good outcome for the voter. It just happened to be that the politician was "unlucky" to have had incorrect infomration. Conversely, when voters re-elect the incumbent for the good 
outcome where $p=B$ and $\omega=B$, they "reward" ideological politicians for acting out of pure self-interest (that is aligned with the voter's interest only by happenstance). Thus, although voters "reward" politicians for good outcomes and "punish" them for bad ones, it is unlikely that the preference for accountability is motivated by fairness concerns or that it is a form of retribution for selfish behavior. It therefore appears to be distinct from explanations of behavior in ultimatum game and public goods experiments.

To test whether a preference for accountability contributes to retrospective voting, the forward payoff treatment removes any temptation that voters may have to sanction an office-motivated incumbent's performance by making the politician's policy choice completely irrelevant to the voter's payoffs. ${ }^{27}$ That is, voters are only rewarded in the FP treatment for the type of politician that they elect to office. Thus, rational voters in the FP treatment must necessarily be forward-looking. Whereas some subjects may have failed to consider the selection problem in the baseline experiment, they are now forced to confront it.

The parameters in the FP treatment were the same as in the baseline delegate sessions except that the voter's payoffs were rescaled so that the minimum payoff was 60 and the maximum payoff was 300 (the minimum and maximum voter payoffs in the baseline treatment). Voters received 300 tokens for electing pragmatic politicians with perfect information, 167 tokens for electing pragmatic politicians with noisy information, and 60 tokens for electing ideological politicians. The rescaling is an affine transformation of the original payoffs, so that the modified game is strategically equivalent to the baseline game in the delegate sessions. The perfect Bayesian equilibrium in the FP treatment is therefore the delegate equilibrium. Even if the results do not perfectly conform to the equilibrium, the preference for accountability hypothesis implies that voters will be more likely to re-elect incumbents when $p=A$ and $\omega=B$ and less likely to re-elect them when $p=B$ and $\omega=B$ in the FP treatment than in the baseline experiment. In other words, voters will be less

\footnotetext{
${ }^{27}$ Note that in this modification, the policy choices of office-motivated politicians become pure cheap talk, although the presence of policy-motivated politicians means that policy choices are not cheap talk for all politicians.
} 
likely to use a retrospective voting rule.

[Figure 4 about here.]

Figure 4 shows that in two sessions (36 total subjects), voters indeed were less likely to use a retrospective rule than in the baseline experiment. When $p=A$ and $\omega=B$, voters are more likely to re-elect the incumbent than in the baseline: the $52 \%$ re-election rate in the $\mathrm{FP}$ treatment is a 17 percentage point increase over the baseline $(p<0.01$, one-tailed). Similarly, when $p=B$ and $\omega=B$, subjects in the FP treatment are less likely to re-elect the incumbent: the $66 \%$ re-election rate is 21 percentage points less than in the baseline $(p<0.01$, one-tailed). Although behavior in the FP treatment represents a significant decrease in retrospective voting behavior, the equilibrium prediction of a policybased voting rule (Hypothesis 3) can still be rejected since voters remain more likely to re-elect incumbents when $p=\omega$ than when $p \neq \omega$. Nevertheless, the results provide support for the behavioral hypothesis that voters' preference for accountability partly account for the behavior in the baseline experiment. But even when payoffs from past policy choices are removed and voters must necessarily grapple with the selection problem, they are unable to do so in a fully optimal Bayesian manner, which provides further support for the bounded rationality interpretation.

\section{Conclusion}

The experimental findings presented here pose a challenge for theories of democratic selection and, more generally, for theories of elections that emphasize voter learning. The formal theoretical literature is grounded in a clear and compelling logical argument that rational forwardlooking voters will focus on selection (Alesina and Rosenthal 1995, Ashworth 2005, Ashworth and Bueno de Mesquita 2008, Fearon 1999), thereby inducing politicians to distort their policy choices and to pander (Canes-Wrone, Herron and Shotts 2001, Maskin and Tirole 2004, Stasavage 2004). Yet in a carefully controlled laboratory experiment that closely 
implements the strategic environment of a theoretical model, subjects do not fall prey to the "delegate trap." Instead, there is a strong behavioral tendency to vote retrospectively, which in turn induces office-motivated politicians to act in the voter's best interest. ${ }^{28}$ While the findings do not imply that social scientists should entirely dispense with formal models of elections and electoral accountability (as game theoretic models are valuable for explicitly highlighting the strategic relationship between elites and masses), they do call into question important rationality assumptions. Future modeling efforts might retain core rationality assumptions while making suitable modifications in the vein of behavioral game theory (Camerer 2003, Binswanger and Prufer 2010, Schuett and Wagner 2007) or retain notions of goals and preferences while relying on alternative formulations of decision-making processes such as heuristic or adaptive behavior (Bendor, Diermeier, Siegel and Ting 2011).

Two causal mechanisms, both of which are supported by additional experimental analysis, explain why the observed behavior is inconsistent with the strong behavioral assumptions embodied in theoretical models. First, finding the optimal solution to the selection problem is a cognitively demanding task, especially when the solution requires strategic and Bayesian inference. Voters must ask themselves: If an incumbent chose a poor policy, was it because of a mistake or because of the politician's divergent goals? And if the incumbent chose a good policy, was it because of luck or skill? Drawing the correct inference requires a great deal of cognitive sophistication, likely beyond the degree possessed by the typical citizen.

In the face of cognitively difficult decision problems, boundedly rational individuals tend to fall back on simple decision rules. Traditional retrospective voting is certainly a

\footnotetext{
${ }^{28}$ Additional experimental research is needed to explore the extent to which this result holds in different kinds of strategic environments. Such evidence is already beginning to emerge. For example, Landa (2010) finds in an experiment with an effort-based environment that subjects also engage in sanctioning when the model predicts pure learning (selection) behavior. However, in a public goods experiment with elections, Hamman, Weber and Woon (2011) suggest that selection rather than sanctioning accounts for socially optimal outcomes. In a spatial framework, Collier, McKelvey, Ordeshook and Williams (1987) find that retrospective voting induces politicians to act in the interests of a majority of voters. An interesting extension would be to allow for the incumbent to "justify" their choice via cheap talk communication to see whether this reinforces or discourages sanctioning.
} 
simple decision rule: reward incumbents for good outcomes and punish them for bad ones. The simplified type treatment indicates not only that the complexity of the decision problem is a partial cause but also that strategic inferences are difficult to make even in relatively simple settings. The information choice treatment reinforces this conclusion.

These results speak to recent debates about whether citizens learn in a "rational," unbiased Bayesian manner (Bullock 2009, Gerber and Green 1998) or whether information processing is marked by partisan bias and motivated reasoning (Bartels 2002, Gaines et al. 2008, Taber and Lodge 2006). The experimental results suggest that even in the absence of partisan motivations, learning may fail to be fully rational or Bayesian because citizens make inferential mistakes and are unable to correctly utilize the information at their disposal.

However, the experimental evidence also suggests that in addition to cognitive limits, a preference for accountability also causes retrospective voting behavior. That is, the data are consistent with the hypothesis that some subjects chose to hold incumbents accountable and thought of the voting problem as one of sanctioning rather than selection. Such reasoning is myopic and boundedly rational because it fails to take into consideration the effects of retrospective voting on future outcomes. When subjects were forced to consider the problem as one of selection in the forward payoff treatment, they were indeed more likely to reward politicians for choosing the correct action, but their behavior still did not come close to that predicted by sequential, Bayesian rationality.

Although the strength of retrospective voting found in the lab is consistent with the voluminous empirical literature on economic voting (e.g., Kramer 1971, Nadeau and LewisBeck 2001, Nordhaus 1975, Norpoth 1996), the results raise important concerns about the interpretation of observational analyses and the rationality of their behavioral underpinnings. First, the experimental evidence suggests a degree of bounded rationality that is inconsistent with not only formal theories but also with theories of prospective economic voting that require sophisticated voters to form rational expectations (e.g., Mackuen, Erikson and Stimson 1992) or solve signal extraction problems (e.g., Duch and Stevenson 2010). 
Second, although Fiorina's (1981) seminal analysis seemed to put to rest any notion that Key's (1966) simple reward-punishment theory should be taken seriously, the experimental results suggest that the traditional theory retains a degree of empirical validity. ${ }^{29}$

The interpretation of traditional retrospective voting as a heuristic employed by voters when faced with a cognitively complex inference problem also bears a resemblence to the standard rational choice interpretation of retrospective voting as an informational shortcut (Downs 1957, Fiorina 1981), but the interpretations differ in an important respect. In the rational choice interpretation, retrospective evaluations (and party identification in Fiorina's formulation) are tools for maximizing utility whereas in the bounded rationality view they are attempts to do so. Psychologists recognize that a heuristic may sometimes be an effective "fast and frugal" solution if it is well-suited to the choice environment (e.g., Gigerenzer 2004), but in other situations may lead to biases and judgmental errors (e.g., Tversky and Kahneman 1974). In the Fox and Shotts (2009) model, retrospective voting works well because it avoids pandering and encourages politicians to act in voters' interests, but for other types of policy, boundedly rational behavior may instead undermine accountability (Healy and Malhotra 2009).

Under what conditions are voters more likely to rely on retrospective voting than other decision rules? Does the use of the heuristic vary with information about the link between policies and outcomes or with institutional variation in the policy-making process? What are the general conditions under which retrospective voting encourages good behavior by politicians? While there is some research that investigates the effectiveness of heuristics in non-strategic voting environments (e.g., Lau and Redlawsk 2001), many questions about heuristic use in the strategic context of democratic accountability remain for theoretical and empirical investigation.

\footnotetext{
${ }^{29}$ This is consistent with recent evidence of "blind" retrospective voting (e.g., Achen and Bartels 2004, Healy, Malhotra and Mo 2010, Wolfers 2002). See also Arceneaux and Stein (2006) and Malhotra and Kuo (2008).
} 


\section{References}

Achen, Christopher H. and Larry M. Bartels. 2004. "Blind Retrospection: Electoral Responses to Drought, Flu, and Shark Attacks." Working Paper, Princeton University.

Alesina, Alberto and Howard Rosenthal. 1995. Partisan Politics, Divided Government, and the Economy. Cambridge University Press.

Arceneaux, Kevin and Robert M. Stein. 2006. "Who is Held Responsible When Disaster Strikes? The Attribution of Responsibility for a Natural Disaster in an Urban Election." Journal of Urban Affairs 28(1):43-53.

Ashworth, Scott. 2005. "Reputational Dynamics and Political Careers." Journal of Law, Economics, and Organization 21(2):441.

Ashworth, Scott and Ethan Bueno de Mesquita. 2008. "Electoral Selection, Strategic Challenger Entry, and the Incumbency Advantage." The Journal of Politics 70(04):10061025.

Banks, Jeffrey S. and Rangarajan K. Sundaram. 1993. Adverse Selection and Moral Hazard in a Repeated Elections Model. In Political Economy: Institutions, Competition, and Representation: Proceedings of the Seventh International Symposium in Economic Theory and Econometrics. Cambridge University Press.

Baron, J. and J.C. Hershey. 1988. "Outcome Bias in Decision Evaluation." Journal of Personality and Social Psychology 54(4):569-579.

Bartels, Larry M. 2002. "Beyond the Running Tally: Partisan Bias in Political Perceptions." Political Behavior 24(2):117-150.

Bendor, Jonathan, Daniel Diermeier, David A. Siegel and Michael M. Ting. 2011. A Behavioral Theory of Elections. Princeton University Press.

Bendor, Jonathan, Sunil Kumar and David A. Siegel. 2010. "Adaptively Rational Retrospective Voting." Journal of Theoretical Politics 22(1):26.

Binswanger, Johannes and Jens Prufer. 2010. "Democracy, Populism, and (Un)bounded Rationality." TILEC Discussion Paper No. 2008-040.

Bullock, John G. 2009. "Partisan Bias and the Bayesian Ideal in the Study of Public Opinion." Journal of Politics 71(03):1109-1124.

Camerer, Colin. 2003. Behavioral Game Theory: Experiments in Strategic Interaction. Russell Sage Foundation and Princeton University Press.

Camerer, Colin, George Loewenstein and Martin Weber. 1989. "The Curse of Knowledge in Economic Settings: An Experimental Analysis." Journal of Political Economy $97(5): 1232-54$. 
Canes-Wrone, Brandice, Michael C. Herron and Kenneth W. Shotts. 2001. "Leadership and Pandering: A Theory of Executive Policymaking." American Journal of Political Science 45(3):532-50.

Chou, Eileen, Margaret McConnell, Rosemarie Nagel and Charles R. Plott. 2009. "The Control of Game Form Recognition in Experiments: Understanding Dominant Strategy Failures in a Simple Two Person "Guessing" Game." Experimental Economics 12(2):159179 .

Chrostowski, J.J. and R.C. Griggs. 1985. "The Effects of Problem Content, Instructions, and Verbalization Procedures on Wasons Selection Task." Current Psychological Research and Review 4:99-107.

Clarke, Harold D. and Marianne C. Stewart. 1994. "Prospections, Retrospections, and Rationality: The 'Bankers' Model of Presidential Approval Reconsidered." American Journal of Political Science 38(4):1104-23.

Collier, Kenneth E., Richard D. McKelvey, Peter C. Ordeshook and Kenneth C. Williams. 1987. "Retrospective Voting: An Experimental Study." Public Choice 53(2):101-130.

Cooper, David J. and John H. Kagel. 2003. "The Impact of Meaningful Context on Strategic Play in Signaling Games." Journal of Economic Behavior 83 Organization 50(4):311337.

Cosmides, Leda. 1989. "The Logic of Social Exchange: Has Natural Selection Shaped How Humans Reason? Studies With the Wason Selection Task." Cognition 31(3):187-276.

Downs, Anthony. 1957. An Economic Theory of Democracy. HarperCollins.

Duch, Raymond M. and Randy Stevenson. 2010. "'The Global Economy, Competency, and the Economic Vote"." Journal of Politics 72(1):105-123.

Evans, Geoffrey and Robert Anderson. 2006. "The Political Conditioning of Economic Perceptions." Journal of Politics 68(1):194-207.

Fearon, James D. 1999. Electoral Accountability and the Control of Politicians: Selecting Good Types versus Sanctioning Poor Performance. In Democracy, Accountability, and Representation, ed. A. Przeworski, S.C. Stokes and B. Manin. Cambridge University Press.

Fehr, Ernst and Simon Gächter. 2000. "Fairness and Retaliation: The Economics of Reciprocity." Journal of Economic Perspectives 14(3):159-181.

Ferejohn, John. 1986. "Incumbent Performance and Electoral Control." Public Choice $50(1): 5-25$.

Fiorina, Morris A. 1981. Retrospective Voting in American National Elections. New Haven, Conn.: Yale University Press. 
Fischbacher, Urs. 2007. "z-Tree: Zurich Toolbox for Ready-Made Economics Experiments." Experimental Economics 10:171-8.

Fischhoff, Baruch. 1975. "Hindsight $\neq$ Foresight: The Effect of Outcome Knowledge on Judgment Under Uncertainty." Journal of Experimental Psychology: Human Perception and Performance 104:288-99.

Fox, Justin. 2007. "Government Transparency and Policymaking." Public Choice 131(1):2344.

Fox, Justin and Kenneth W. Shotts. 2009. "Delegates or Trustees? A Theory of Political Accountability." Journal of Politics 71(4):1225-37.

Gaines, Brian J., James H. Kuklinski, Paul J. Quirk, Buddy Peyton and Jay Verkuilen. 2008. "Same Facts, Different Interpretations: Partisan Motivation and Opinion on Iraq." Journal of Politics 69(04):957-974.

Gerber, Alan and Donald P. Green. 1998. "Rational Learning and Partisan Attitudes." American Journal of Political Science 42(3):794-818.

Gigerenzer, Gerd. 2004. Fast and Frugal Heuristics: The Tools of Bounded Rationality. In Blackwell Handbook of Judgment and Decision Making, ed. D.J. Koehler and N. Harvey. Blackwell.

Gordon, Sanford C., Gregory A. Huber and Dimitri Landa. 2007. "Challenger Entry and Voter Learning." American Political Science Review 101(02):303-320.

Hamman, John R., Roberto A. Weber and Jonathan Woon. 2011. "An Experimental Investigation of Electoral Delegation and the Provision of Public Goods." American Journal of Political Science 55(4):738-752.

Healy, Andrew, Neil Malhotra and Cecilia Hyunjung Mo. 2010. "Irrelevant Events Affect Voters' Evaluation of Government Performance." Proceedings of the National Academy of Sciences 107(29):12804-12809.

Healy, Andrew W. and Neil Malhotra. 2009. "Myopic Voters and Natural Disaster Policy." American Political Science Review 103(3):387-406.

Hertwig, Ralph and Andreas Ortmann. 2001. "Experimental Practices in Economics: A Methodological Challenge for Psychologists?" Behavioral and Brain Sciences 24:383403.

Key, V.O., Jr. 1966. The Responsible Electorate. Belknap Press.

Kotovsky, K., J.R. Hayes and H.A. Simon. 1985. "Why are Some Problems Hard? Evidence from Tower of Hanoi." Cognitive Psychology 17(2):248-294.

Kramer, Gerald. 1971. "Short-Term Fluctuations in U.S. Voting Behavior." American Political Science Review 65:131-43. 
Landa, Dimitri. 2010. "Selection Incentives and Accountability Traps: A Laboratory Experiment." Paper presented at the Annual Meeting of the American Political Science Association (Washington, DC).

Lau, Richard and David Redlawsk. 2001. "Advantages and Disadvantages of Cognitive Heuristics in Political Decision Making." American Journal of Political Science 45:97171.

Lewis-Beck, Michael S., Richard Nadeau and Angelo Elias. 2008. "Economics, Party, and the Vote: Causality Issues and Panel Data." American Journal of Political Science $52(1): 84-95$.

Loewenstein, George. 1999. "Experimental Economics from the Vantage Point of Behavioral Economics." The Economic Journal 109:F25-F34.

Mackuen, Michael B., Robert S. Erikson and James A. Stimson. 1992. "Peasants or Bankers? The American Electorate and the U.S. Economy." American Political Science Review 86(3):597-611.

Malhotra, Neil and Alexander G. Kuo. 2008. "Attributing Blame: The Public's Response to Hurricane Katrina." The Journal of Politics 70(01):120-135.

Manin, Bernard. 1997. The Principles of Representative Government. Cambridge University Press.

Maskin, Eric and Jean Tirole. 2004. "The Politician and the Judge: Accountability in Government." The American Economic Review 94(4):1034-1054.

McKelvey, McLennan and Turocy. 2007. "Gambit: Software Tools for Game Theory, Version 0.2007.01.30." www.gambit-project.org.

McKelvey, Richard D. and Thomas R. Palfrey. 1995. "Quantal Response Equilibria in Normal Form Games." Games and Economic Behavior 10:6-37.

McKelvey, Richard D. and Thomas R. Palfrey. 1998. "Quantal Response Equilibria in Extensive Form Games." Experimental Economics 1:9-41.

Miller, Warren E. and Donald E. Stokes. 1963. "Consituency Influence in Congress." American Political Science Review 57(1):45-56.

Nadeau, Richard and Michael Lewis-Beck. 2001. "National Economic Voting in U.S. Presidential Elections." Journal of Politics 63:159-81.

Nordhaus, William. 1975. "The Political Business Cycle." Review of Economic Studies 42:169-90.

Norpoth, Helmut. 1996. "Presidents and the Prospective Voter." Journal of Politics $58(3): 776-92$. 
Ostrom, Elinor, James Walker and Roy Gardner. 1992. "Covenants With and Without a Sword: Self-Governance is Possible." American Political Science Review pp. 404-417.

Patty, John W. and Roberto A. Weber. 2007. "Letting the Good Times Roll: A Theory of Voter Inference and Experimental Evidence." Public Choice 130:293-310.

Schuett, Florian and Alexander K. Wagner. 2007. "Evaluating Political Decision Makers: With the Benefit of Hindsight Bias?" Working paper: Toulouse School of Economics.

Simon, Herbert A. 1955. "A Behavioral Model of Rational Choice." The Quarterly Journal of Economics 69(1):99-118.

Simon, Herbert A. 1990. "Invariants of Human Behavior." Annual Review of Psychology 41(1):1-20.

Stasavage, David. 2004. "Open-door or Closed-door? Transparency in Domestic and International Bargaining." International Organization 58(04):667-703.

Taber, Charles S. and Milton Lodge. 2006. "Motivated Skepticism in the Evaluation of Political Beliefs." American Journal of Political Science 50(3):755-769.

Tversky, Amos and Daniel Kahneman. 1974. "Judgment Under Uncertainty: Heuristics and Biases." Science 185(4157):1124-1131.

Wason, P.C. and Diana Shapiro. 1971. "Natural and Contrived Experience in a Reasoning Problem." Quarterly Journal of Experimental Psychology 23:63-71.

Wolfers, Justin. 2002. "Are Voters Rational? Evidence from Gubernatorial Elections." Working Paper: Stanford GSB. 


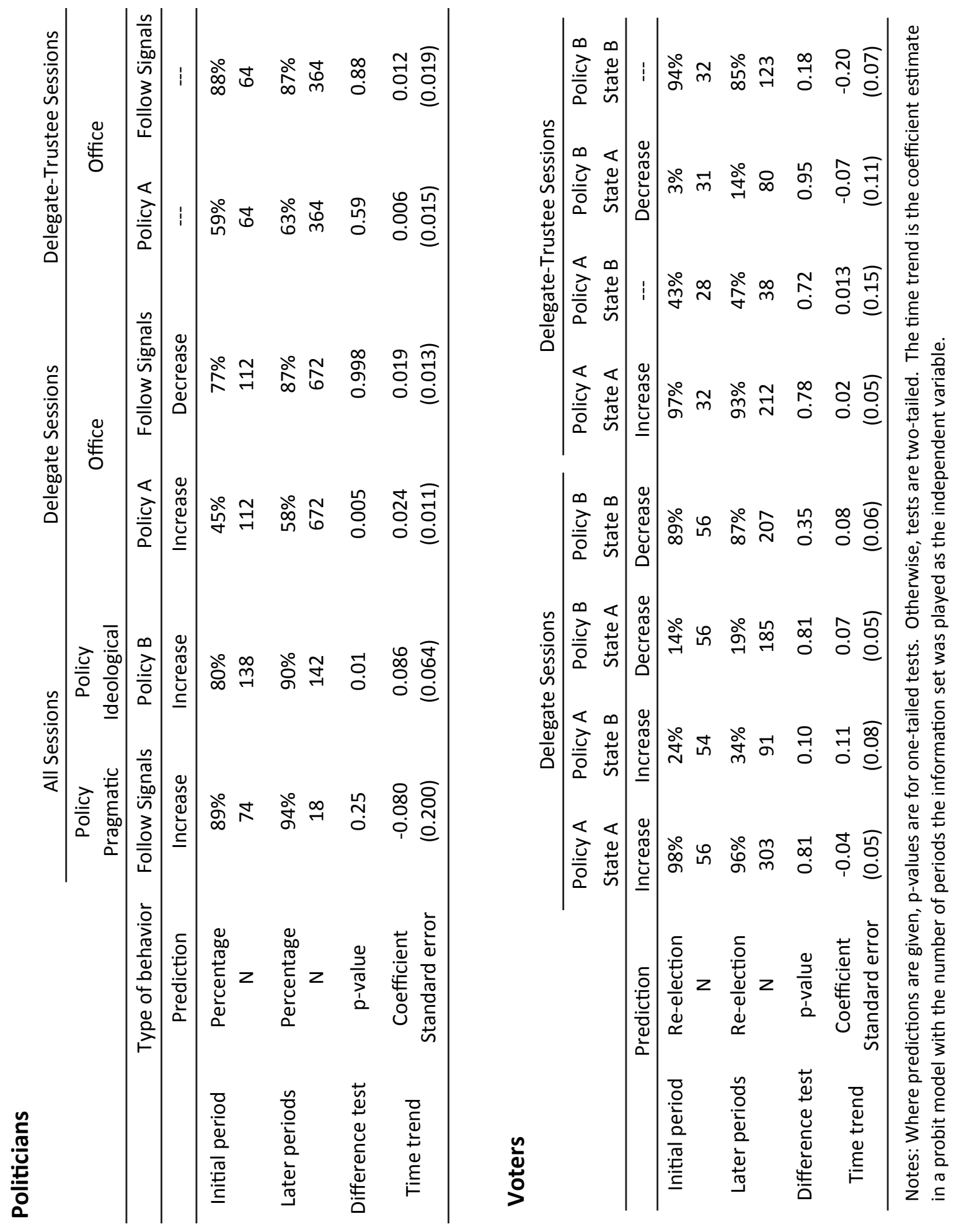

Table 1: Learning 


\begin{tabular}{|c|c|c|c|c|}
\hline & \multicolumn{4}{|c|}{ Incumbent Re-elected } \\
\hline & \multicolumn{2}{|c|}{ Policy A } & \multicolumn{2}{|c|}{ Policy B } \\
\hline & Pct Re-election & $\begin{array}{c}\text { p value } \\
\text { (one-tailed) }\end{array}$ & Pct Re-election & $\begin{array}{c}p \text { value } \\
\text { (one-tailed) }\end{array}$ \\
\hline \multirow[t]{2}{*}{ Baseline } & $80 \%$ & --- & $55 \%$ & --- \\
\hline & $(880)$ & & (770) & \\
\hline \multirow[t]{2}{*}{ Policy Information } & $85 \%$ & 0.02 & $42 \%$ & $<0.01$ \\
\hline & (379) & & $(233)$ & \\
\hline \multirow[t]{2}{*}{ Information Choice } & $89 \%$ & $<0.01$ & $52 \%$ & 0.26 \\
\hline & $(227)$ & & $(160)$ & \\
\hline
\end{tabular}

Notes: $\mathrm{N}$ in parentheses; $\mathrm{p}$ values for $\mathrm{t}$-tests of differences from baseline

Table 2: Policy information and information choice treatments 


\begin{tabular}{lcccc} 
& \multicolumn{4}{c}{ Incumbent Re-elected } \\
\cline { 2 - 5 } & $\begin{array}{l}\text { Policy A } \\
\text { State A }\end{array}$ & $\begin{array}{c}\text { Policy A } \\
\text { State B }\end{array}$ & $\begin{array}{c}\text { Policy B } \\
\text { State A }\end{array}$ & $\begin{array}{c}\text { Policy B } \\
\text { State B }\end{array}$ \\
\hline Baseline & $95 \%$ & $35 \%$ & $16 \%$ & $87 \%$ \\
& $(603)$ & $(211)$ & $(352)$ & $(418$ \\
Information Choice & $100 \%$ & $0 \%$ & $11 \%$ & $96 \%$ \\
& $(51)$ & $(14)$ & $(37)$ & $(51)$ \\
\hline p value (two-tailed) & 0.11 & 0.01 & 0.41 & 0.07 \\
\hline
\end{tabular}

Notes: $\mathrm{N}$ in parentheses; $\mathrm{p}$ values for $\mathrm{t}$-tests of differences from baseline

Table 3: Voting with irrelevant information in information choice treatment 

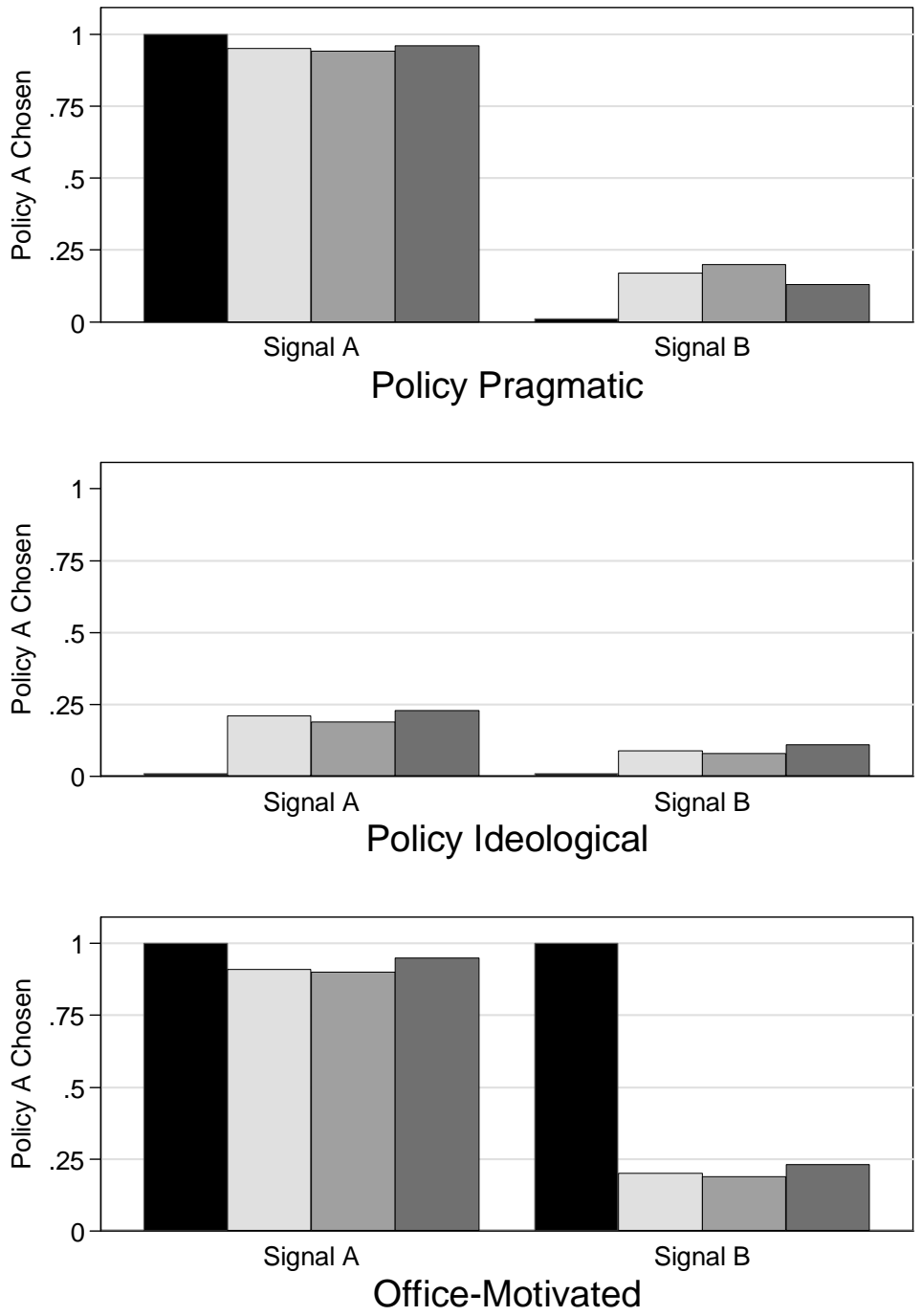

Predicted (Delegate) Delegate Sessions

Figure 1: Politician behavior 

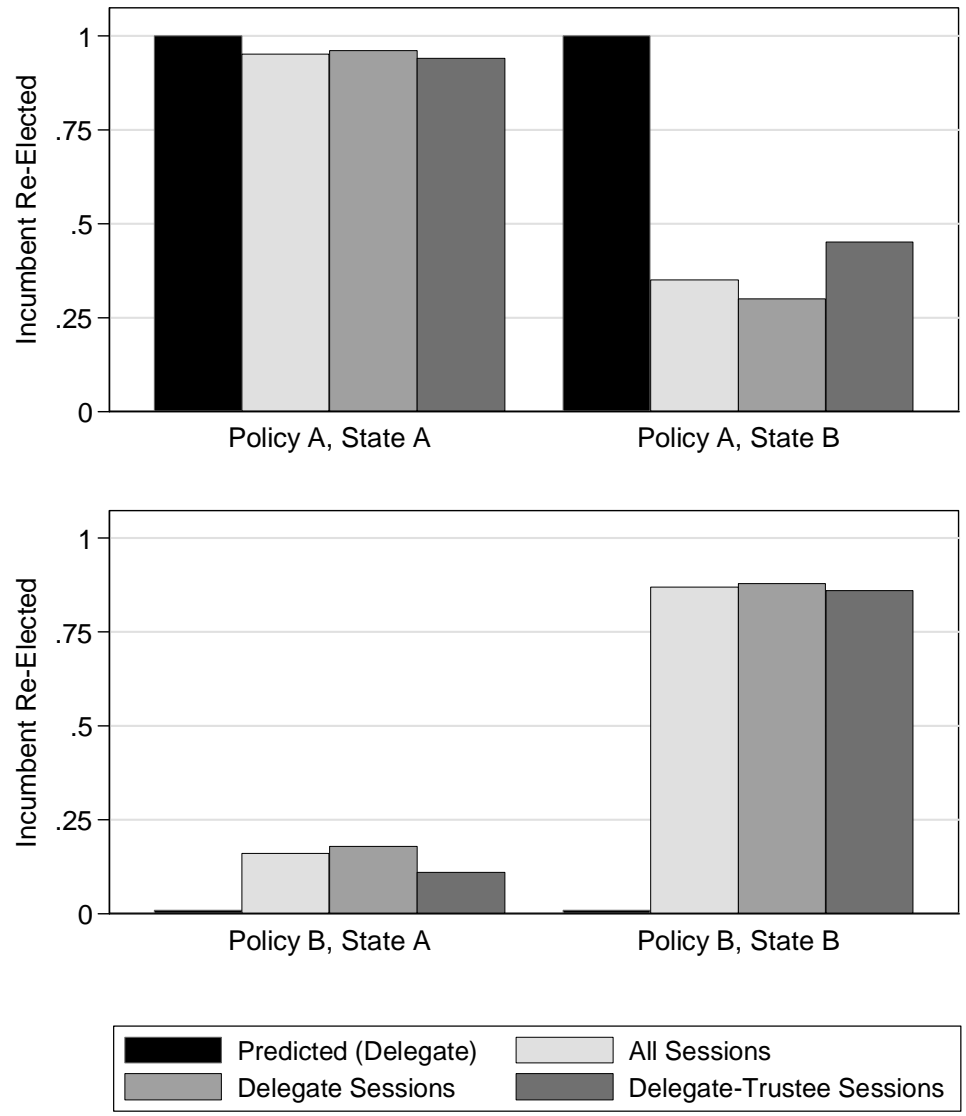

Figure 2: Voter behavior 


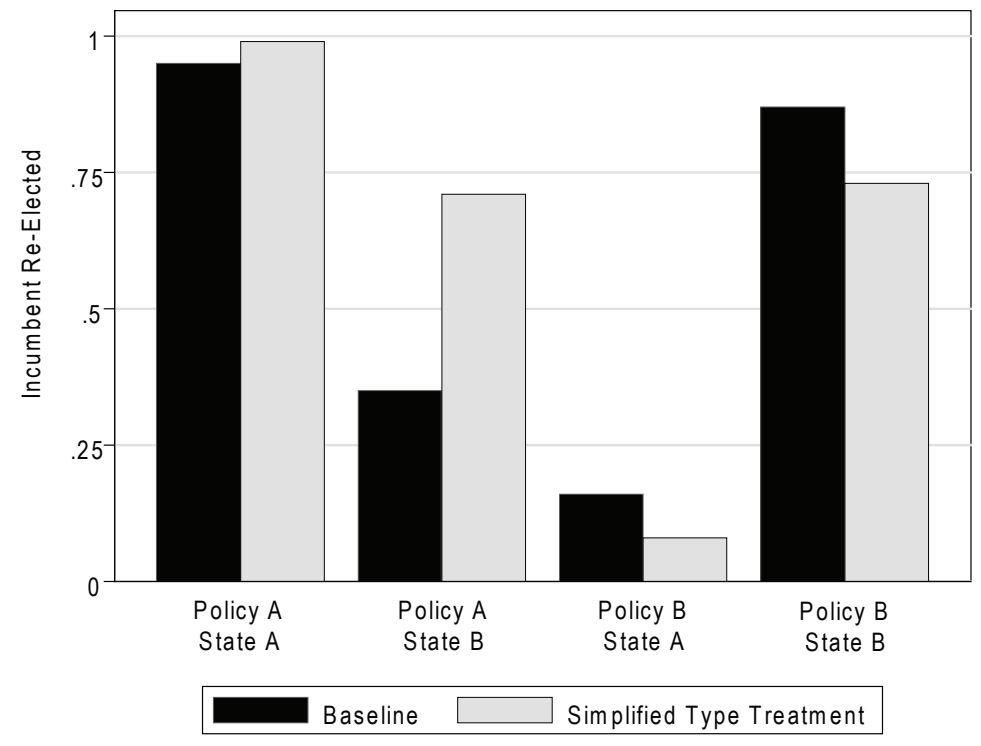

Figure 3: Simplified type treatment 


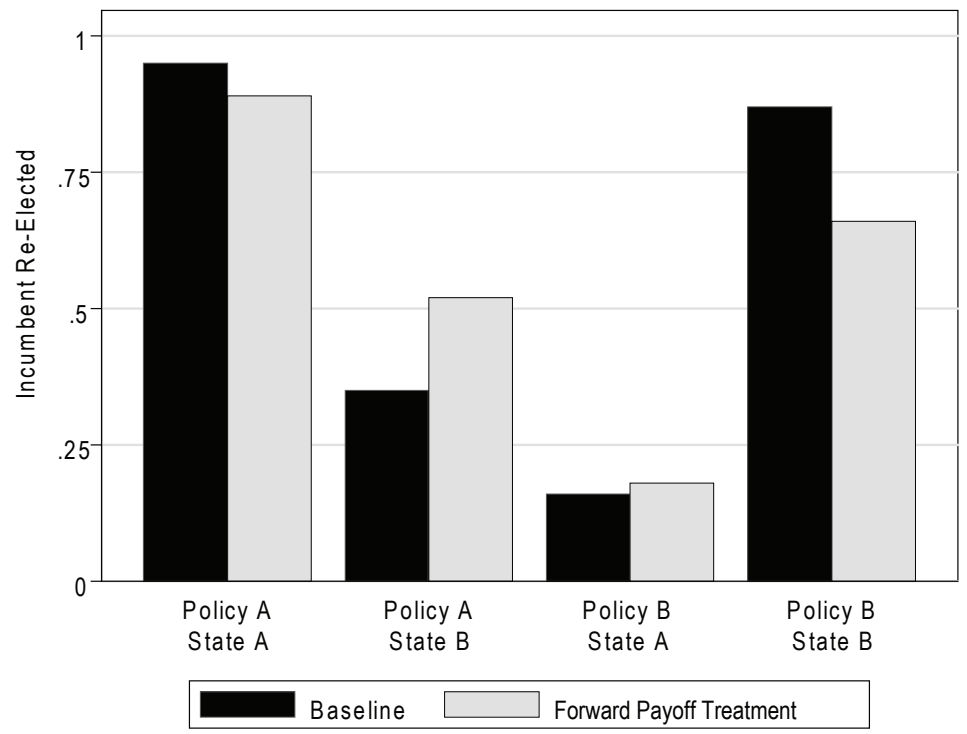

Figure 4: Forward payoff treatment 